\title{
Heating and Cooling of Air Flowing Through an Underground Tunnel ${ }^{*}$
}

\author{
B. A. Peavy
}

(April 25, 1961)

\begin{abstract}
Fresh or outside air needed for ventilating underground installations is introduced through shafts or tunnels. For a shaft or tunnel in continuous use, heat is transferred from the air to the rock in summer and from the rock to the air in the winter, thereby reducing the seasonal cooling and heating loads of the underground installation. The possible benefit of this tempering effect in reducing the size and operating cost of the air cooling and heating system of the installation cannot be realized in the design stage without a reliable means of estimating the influence of the tunnel. In this paper, equations and functions for computing the tempering effect are developed by mathematical analysis of the problem, assuming a sinusoidal variation of the outside air temperature, and are shown to be in substantial accordance with experimental results obtained in tests made in a small-scale model tunnel.
\end{abstract}

\section{Introduction}

When outside air for ventilating an underground chamber, or for other purposes, is drawn continuously through a long tunnel or airway in rock, heat interchange between the rock and the flowing air considerably reduces, by the time the air reaches the far end, the fluctuations of temperature to which the entering outside air was subject as a result of diurnal and seasonal changes. The tempering thus effected by the rock in cooling summer air and heating winter air may have an important benefit in reducing the design size and operating cost of the air cooling and heating systems of an underground installation. Mine and tunnel air ventilation studies $[1,2]^{1}$ have shown qualitatively the reduction of the fluctuations of temperature of outside air flowing into mines, but have ventured no analysis of this process for prediction of temperatures and heat flow quantities.

This paper presents the results of a mathematical analysis of the heat transfer between the air and the rock, assuming that the temperature of the entering air varies periodically and sinusoidally. For the case of long tunnels in rock, diurnal and short-time climatic fluctuations are quickly attenuated and damped out in the first part of the tunnel. Consequently, the significant fluctuation is the seasonal or annual periodic variation in outdoor air temperature, which is known to approximate a sinusoidal oscillation [3].

The mathematical solutions obtained are for the case of dry air. Efforts to take account of heat exchanges between the air and rock due to condensation of moisture from the air, or its evaporation from the rock, introduce mathematical complexities that preclude analytic solutions. However, the results obtained for dry air are conservative in regard to the amounts of heat transferred between the air and rock, as the effect of latent heat transfer

\footnotetext{
*This work was supported by the Protective Structures Branch, Office of the ${ }^{*}$ This work was supported by the
Chief of Engineers, U.S. Army.

1 Figures in brackets indicate the literature references at the end of this paper.
}

is to increase the total heat exchanges to values greater than those given by the equations for dry air conditions.

To determine the validity of the analytical treatment for design purposes, experiments were conducted on a small-scale model underground tunnel, and the data thus obtained were compared with the results predicted by the analytical method.

\section{Analysis}

To obtain a mathematical expression for the heattransfer characteristics of the rock surrounding an air-intake tunnel, let us assume that the tunnel takes the form of a hollow cylinder. Let us further assume that the temperature $T_{0}$ of the air entering the tunnel varies periodically about its mean annual value $T_{i}$ in accordance with the following relationship :

$$
\left(T_{0}-T_{i}\right)=\left(T_{0(\max )}-T_{i}\right) \cos \omega t
$$

where the angle $\omega t$ increases by $2 \pi$ radians $\left(360^{\circ}\right)$ in 1 year.

For convenience in the development, we will use a subrogated temperature $\theta$, defined as $\left(T-T_{s}\right)$, where $T_{s}$ is the steady temperature of the rock remotely surrounding the tunnel. On this basis, the subrogated annual mean temperature $\theta_{i}$ of the entering air is $\left(T_{i}-T_{s}\right)$; the amplitude of entering air temperature variation $\left(T_{0(\max )}-T_{i}\right)$ is designated as $\Delta$. Accordingly, the equation above becomes:

$$
T_{0}-T_{s}=\theta_{0}=\theta_{i}+\Delta \cos \omega t .
$$

The hollow cylinder has a radius, $a$, but is otherwise unbounded. The surrounding solid has a conductivity $K$, specific heat $c$, and thermal diffusivity $\alpha$. The air flows in the cylinder at a velocity $V$ in the direction of the positive $x$-axis. It is assumed that in the surrounding rock, heat is conducted radially but not parallel to the axis of the cylinder, and the thermal properties are independent of temperature. 
Let $M^{\prime}$ be the mass of air in contact with unit surface area of the cylinder, $c^{\prime}$ the specific heat of the air, $\theta_{x}$ the air temperature at a distance $x$ and time $t$, and $h$ the coefficient of heat transfer between the air and the cylinder surface. The heat balance equation satisfied by the temperature of the air at distance $x$ is then:

$$
M^{\prime} c^{\prime}\left[\frac{d \theta_{x}}{d t}+V \frac{d \theta_{x}}{d x}\right]+h\left(\theta_{x}-\theta_{a, x}\right)=0
$$

where $\theta_{a, x}$ is the temperature at the surface of the cylinder at distance $x$. The heat transfer at a distance $x$ along the cylinder surface is:

$$
-K\left(\frac{d \theta_{a, x}}{d r}\right)=h\left(\theta_{x}-\theta_{a_{\mathbf{i}} x}\right) .
$$

Equations (1), (2), and (3) provide the boundary conditions for the differential equation for conduction of heat in the solid:

$$
\frac{\partial^{2} \theta_{r, x}}{\partial r^{2}}+\frac{1}{r} \frac{\partial \theta_{r, x}}{\partial r}-\frac{1}{\alpha} \frac{\partial \theta_{r, x}}{\partial t}=0 .
$$

A closely approximate solution for the temperature of the air at distance $x$, assuming steady periodic heat flow, is:

$T_{x}-T_{s}=\theta_{x}=e^{-A A^{\prime}}\left[\Delta \cos \left(\omega t-A B^{\prime}\right)+\theta_{i} \cos A B^{\prime}\right]$

where $A$ involves $x$, and $A^{\prime}$ and $B^{\prime}$ involve $h$.

The derivation of eq (4) is given in section 8.1. The symbols are defined in section 8.3. The functions $A^{\prime}$ and $B^{\prime}$ are plotted on figure 1 for a useful range of the variables $z(=a \sqrt{\omega / \alpha})$ and $n(=a h / K)$.

\section{Model Underground Tunnel}

The model underground tunnel (see fig. 2) was cylindrical, 6 in. in diameter and $33.7 \mathrm{ft}$ long, surrounded by 18 in. of $1: 4$ cement-sand mortar. Several thicknesses of $1 / 2$-in. hair-felt insulation were placed on the outside of the mortar. Air was drawn through the tunnel by a blower and its rate of flow was measured by means of an orifice in the sheet metal duct connecting the tunnel and the blower. At the entrance to the tunnel was a sheet metal duct containing chilled water coils and electric strip heaters. The chilled water coils were used to cool the air to a temperature below the lowest temperature to be encountered at the entrance to the tunnel. The electric strip heaters were governed by a program controller that modulated the heat input to the air so that the entering air temperature varied sinusoidally as a function of time. Thermocouples were located at the entrance and exit and at various locations in the tunnel, and in the surrounding cement mortar, as shown in figure 2. The thermal properties of the cement-sand mortar were determined from samples obtained during pouring operations.

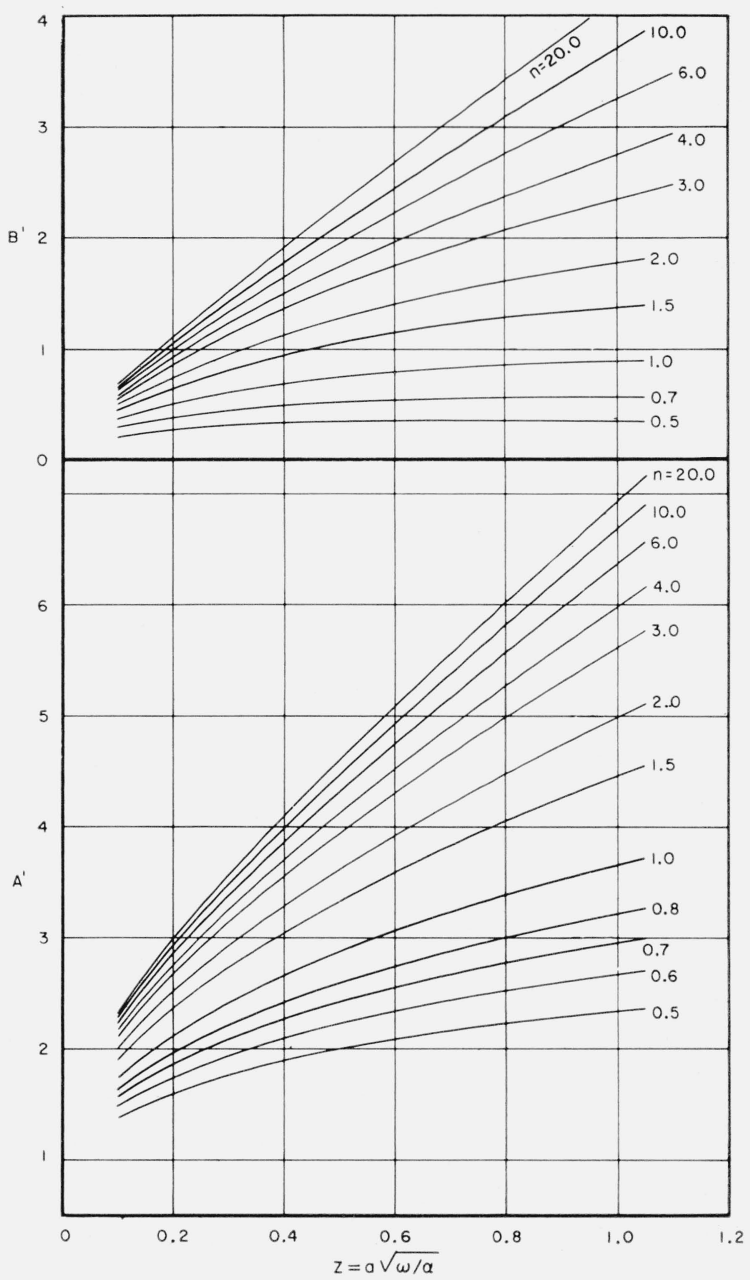

Figure 1. Values of $\mathrm{A}^{\prime}$ and $\mathrm{B}^{\prime}$ as functions of $\mathrm{z}(=\mathrm{a} \sqrt{\omega / \alpha})$ and $\mathrm{n}(=\mathrm{ah} / \mathrm{K})$ for use in $e q(4)$.

Each test consisted of four cycles of temperature variation with a period of $16 \mathrm{hr}$ and an amplitude of about $20^{\circ} \mathrm{F}$. Because the transients due to the initial nonperiodic condition were virtually eliminated in the first two cycles, the last two cycles were used for test results.

\section{Results}

Three tests, in which weight rate of air flow, $W^{\prime}$, was varied, were carried out on the model underground tunnel. The parameters for these tests are given in table 1.

TABLE 1. Test parameters

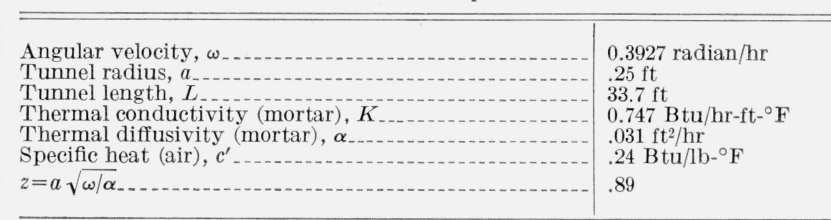

Pertinent test data are given in table 2. The observed entering air temperatures were substan- 


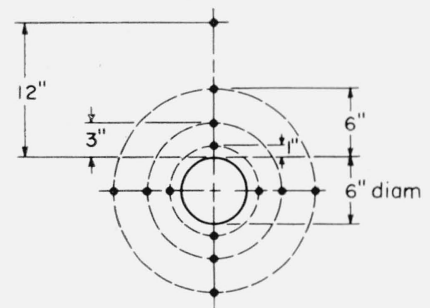

- - thermocouple locations in mortar

AT CROSS SECTIONS A, B, C, D.

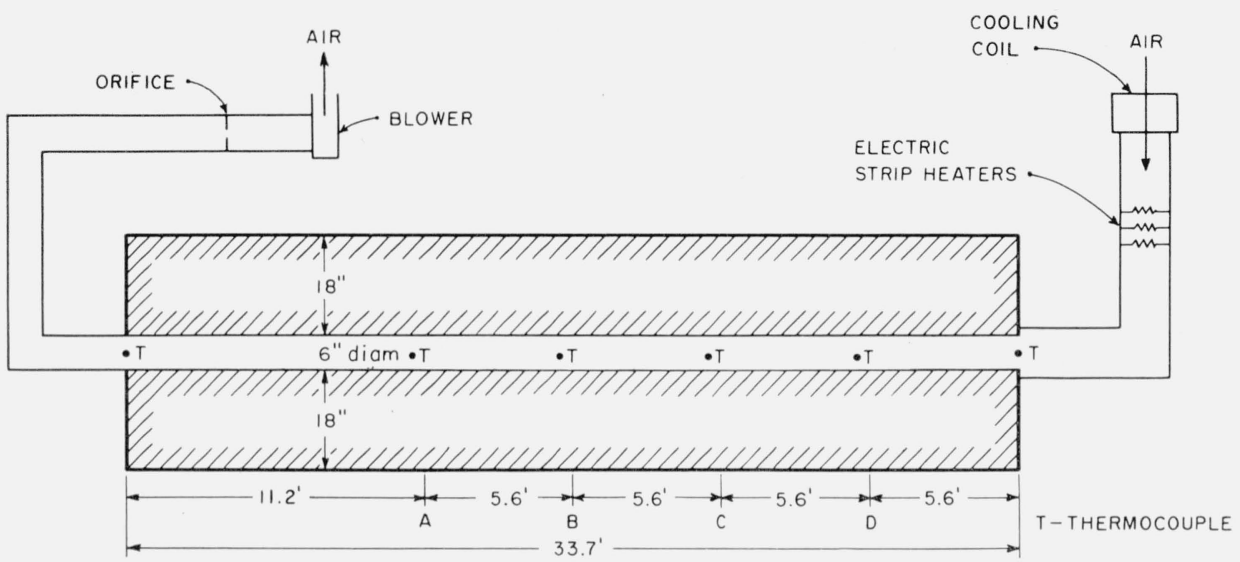

FiguRE 2. Diagrammatic sketch of mode! underground tunnel.

tially sinusoidal and conformed very closely to the equations (within $\pm 0.25^{\circ} \mathrm{F}$ ), of the form of eq (1), set forth in table 3 . The observed values of air temperature at the exit of the tunnel $(L=33.7 \mathrm{ft})$ were found to lag in phase those of the entering air by about 0.14 radian. All experimental quantities involved in eq (4) were determined directly, except, the coefficient of heat transfer, $h$. Since $\theta_{x}$ is a maximum when $\left(\omega t-A B^{\prime}\right)$ equals zero, eq (4) serves for computing $A^{\prime}$, from which the values of $h$ were obtained. The values of $h$ thus computed are presented in table 2 and are compared with values of the forced convection heat transfer coefficient calculated from an equation given by McAdams [4] which, with appropriate properties for the model tunnel and air substituted, is

$$
h=0.016\left(W^{\prime}\right)^{0.8} .
$$

TABLE 2. Data and results from tests on model underground tunnel

\begin{tabular}{|c|c|c|c|}
\hline Test No. & 1 & 2 & 3 \\
\hline $\begin{array}{l}\text { Entering air temps., } T_{0},{ }^{\circ} \mathrm{F}: \\
\text { Maximum } \\
\text { Minimum } \\
\text { Mean, } T_{i} \\
\text { Amplitude, } \Delta\end{array}$ & $\begin{array}{r}109.4 \\
65.2 \\
87.3 \\
22.1\end{array}$ & $\begin{array}{r}101.4 \\
60.0 \\
80.7 \\
20.7\end{array}$ & $\begin{array}{r}100.8 \\
60.0 \\
80.4 \\
20.4\end{array}$ \\
\hline $\begin{array}{l}\text { Leaving air temps., } T_{L},{ }^{\circ} \mathrm{F} \text { : } \\
\text { Maximum } \\
\text { Minimum } \\
\text { Mean } \\
\text { Mean remote temp. of solid (mortar), } T_{s},{ }^{\circ} \mathrm{F}_{-} \\
\theta_{i}=T_{i}-T_{s},{ }^{\circ} \mathrm{F}_{-1} \\
\text { Air flow rate, } W^{\prime}, \mathrm{lb} / \mathrm{hr}\end{array}$ & $\begin{array}{r}95.0 \\
75.0 \\
85.0 \\
83.2 \\
4.2 \\
336.4\end{array}$ & $\begin{array}{r}90.2 \\
71.0 \\
80.6 \\
80.3 \\
0.4 \\
367.9\end{array}$ & $\begin{array}{l}91.5 \\
71.2 \\
81.35 \\
82.2 \\
-1.8 \\
451.2\end{array}$ \\
\hline $\begin{array}{l}\text { Coefficient of heat transfer } h, \mathrm{Btu} / \mathrm{hr}-\mathrm{ft}^{2}{ }^{\circ} \mathrm{F} \text { : } \\
\text { From eq (4) } \\
\text { From eq (5) }\end{array}$ & $\begin{array}{l}1.76 \\
1.69\end{array}$ & $\begin{array}{l}1.85 \\
1.82\end{array}$ & $\begin{array}{l}2.22 \\
2.14\end{array}$ \\
\hline
\end{tabular}

TABLE 3. Applied entering and predicted leaving air temperatures

\begin{tabular}{|c|c|c|}
\hline & Entering air (eq. 1) & Leaving air, $L=33.7$ (eq. 4 ) \\
\hline $\begin{array}{l}\text { Test } 1 \ldots \ldots \\
\text { Test } 2 \ldots \ldots \\
\text { Test } 3 \ldots\end{array}$ & $\begin{array}{l}T_{0}=87.4+22.2 \cos \omega t \\
T_{0}=80.7+20.7 \cos \omega t \\
T_{0}=80.4+20.4 \cos \omega t\end{array}$ & $\begin{array}{l}T_{L}=85.1+10.0 \cos (\omega t-0.1417) \\
T_{L}=80.5+9.7 \cos (\omega t-0.1425) \\
T_{L}=81.3+10.2 \cos (\omega t-0.1457)\end{array}$ \\
\hline
\end{tabular}

Substituting the derived values of $h$, and observed values of $\Delta, \theta_{i}$, and the parameters from table 1 in eq (4), for $L=33.7 \mathrm{ft}$, we obtain the time variation of the leaving air temperature as given by the equations in table 3 . When these equations were plotted, the curves followed the experimental data within $\pm 0.25{ }^{\circ} \mathrm{F}$.

The tempering effect of the tunnel on the air is shown by referring to test No. 3 , table 3 , where the amplitude of the air which was $20.4^{\circ} \mathrm{F}$ at the entrance, was reduced to $10.2^{\circ} \mathrm{F}$ at the exit.

Although the experimental data on air temperature satisfied the analytical solution of the problem, it was felt that further substantiating information was desirable. Equations for the time-variation of temperatures at various radii in the surrounding cementsand mortar were therefore computed from eq (12) for test No. 3, as shown in table 4. Plots of these equations with associated experimental data appear in figure 3 .

TABLE 4. Temperatures in the cement-sand mortar for test No. 3 at cross-section $\mathrm{x}=22.7 \mathrm{ft}$, as predicted by eq (12) of section 8.1

\begin{tabular}{l|l}
\hline \hline & \\
At radius $r=0.33 \mathrm{ft}$ & $T_{x, r}=82.0+3.1 \cos (\omega t-0.733)$ \\
At radius $r=0.50 \mathrm{ft}$ & $T_{x, r}=82.1+1.7 \cos (\omega t-1.169)$ \\
At radius $r=0.75 \mathrm{ft}$ & $T_{x, r}=82.2+0.7 \cos (\omega t-1.815)$ \\
At radius $r=1.25 \mathrm{ft}$ & $T_{x, r}=82.2 \pm 0.1$ \\
\hline
\end{tabular}




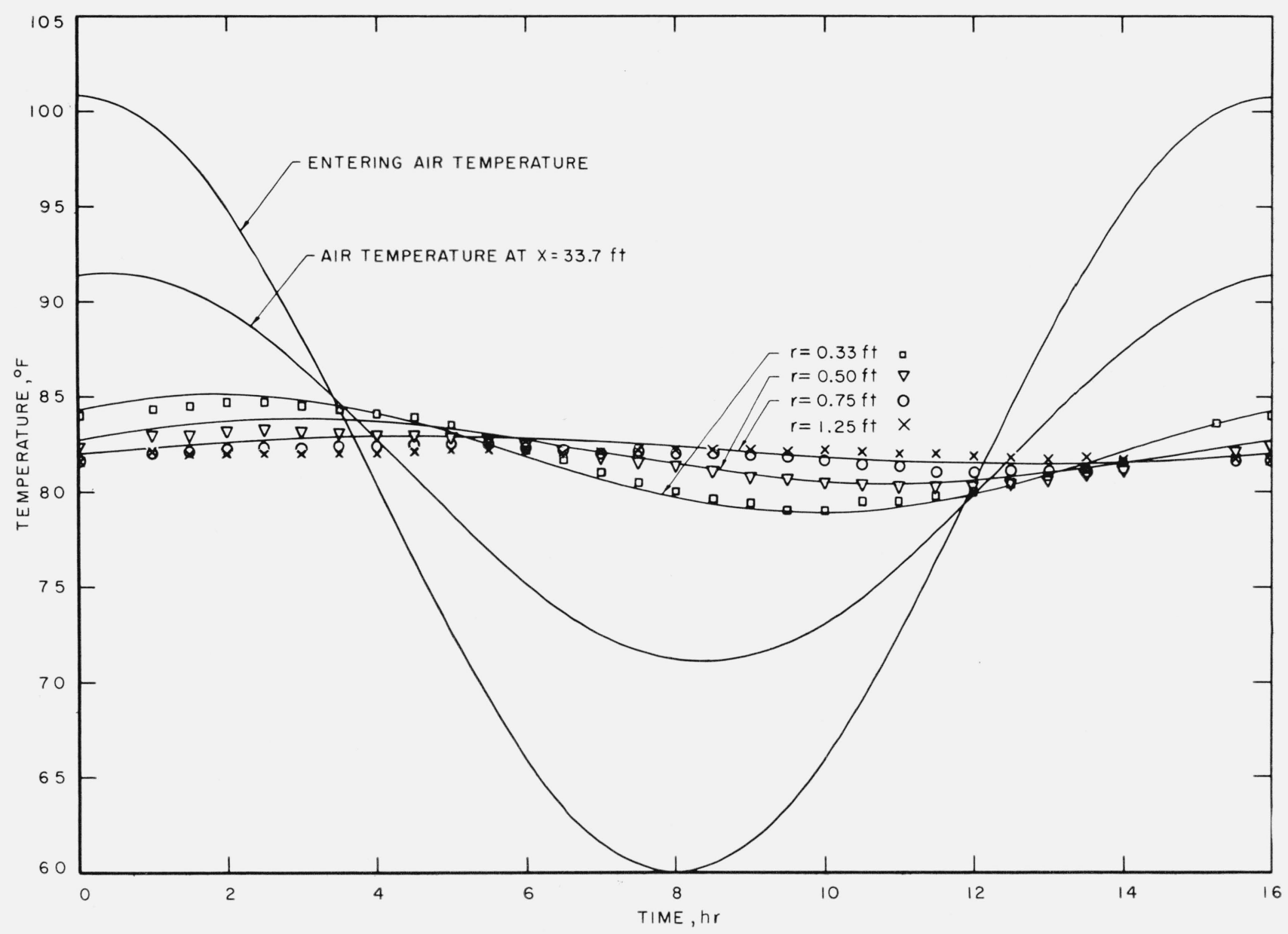

Figure 3. Air and mortar temperature history for model underground tunnel (test No. 3, table 2).

Experimental data for temperatures in mortar at various radii from center of tunnel are denoted by symbols.

\section{Discussion}

For the model tunnel, values of the coefficient of heat transfer were computed from eq (4) and the temperature amplitudes of the leaving air by the method outlined in section 4. A comparison of these coefficients with those determined from eq (5) shows agreement within 5 percent, which is within the probable accuracy of the thermal properties of cement-sand mortar as determined by tests on a few samples.

For tunnels or shafts probable in underground installations, the diameters are likely to be greater than $3 \mathrm{ft}$. Values of the coefficient of heat transfer are not found in the literature for airways of this size and would be particularly difficult to predetermine for the rough and irregular surfaces usually resulting from the excavating process. However, reasonable values may be estimated from compromise considerations of values determined for air flow in small cylinders and air flow parallel to planes, and with an allowance for roughness of surfaces.

Substitution of the parameters and the derived values of $h$ into eq (4) gave the equations for the leaving air temperatures given in table 3 . These equations showed differences less than $0.3^{\circ} \mathrm{F}$ when plotted with the experimental data. Differences less than $0.5^{\circ} \mathrm{F}$ were found between observed temperatures in the surrounding solid (mortar), and those computed by eq (12), as shown in figure 3 .

Because the experimental data agree closely with values computed by eqs (4) and (12), the analytic approach developed in this paper should be applicable for determining temperatures in tunnels of larger size.

\section{Application to a Practical Problem}

To design heating and air conditioning equipment for an underground installation, it is necessary to predict the maximum and minimum temperatures of the air when it is delivered at the installation. From eq (4), the maximum and minimum temperatures occur when $\omega t=A B^{\prime}$ and $\omega t=\pi+A B^{\prime}$, respectively. Using eq (4), these extreme values may be written

$$
\left(\theta_{L}\right)_{m}=e^{-A A^{\prime}}\left( \pm \Delta+\theta_{i} \cos A B^{\prime}\right) .
$$


Figure 1 is a plot of $A^{\prime}$ and $B^{\prime}$ as functions of $n$ and $z$ computed for a range of values expected in a practical problem.

For a sample hypothetical problem, consider a square tunnel with nominal dimensions $7 \mathrm{ft}$ by 7 ft by $2000 \mathrm{ft}$ long, continuously delivering air to an underground installation at a rate of 50,000 cubic feet per minute, or 228,000 pounds per hour. For noncircular cross sections, the equivalent cylindrical radius, $a$, is equal to 2 (cross sectional area)/(perimeter). Assumed parameters for substitution in eq (6) are given in table 5.

TABle 5. Parameters for hypothetical problem

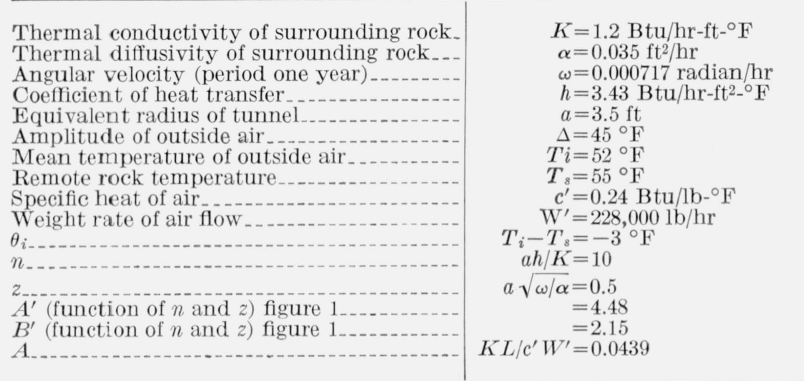

The extreme values predicted by eq (6) are

$$
\left(\theta_{L}\right)_{m}=+34 \text { and }-39^{\circ} \mathrm{F} \text {. }
$$

Because $\theta$ is a subrogated temperature based on a zero value equal to the remote temperature of the surrounding rock, the maximum and minimum air temperatures at the end of the tunnel $(L=2000 \mathrm{ft}$ ) are $55+34=89^{\circ} \mathrm{F}$ and $55-39=16{ }^{\circ} \mathrm{F}$, respectively. The maximum and minimum outside air temperatures (eq (1)) are $97{ }^{\circ} \mathrm{F}$ and $7{ }^{\circ} \mathrm{F}$, respectively. The maximum and minimum air temperatures at the end of the tunnel lag those at the entrance by an angle equal to $A B^{\prime}$, which in this case equals 0.094 radian, equivalent to a time-lag of 5.5 days.

Although the rates of heat loss and gain of the air in a tunnel were not discussed in the experimental portion of this paper, they are of considerable interest in the application to practical problems. For the hypothetical problem, the average rate of cooling by the rock during the cooling season (eq (14), section 8) is 251,000 Btu/hr, or an equivalent of about 21 tons of refrigeration. The average rate of heating by the rock in the heating season is $309,000 \mathrm{Btu} / \mathrm{hr}$, equivalent to the heating effected by burning about 3.35 gallons of fuel oil per hour. The maximum cooling and heating rates are substantially greater than the average, as indicated by eq (13).

\section{Conclusions}

Mathematical equations are derived for computing the tempering effect of a long tunnel in reducing the amplitude of climatic temperature variation of outside air flowing through a tunnel. Results of experiments support the application of the developed equations for design purnocec.
The functions necessary for design use of the equations have been evaluated for a useful range of the parameters and are presented graphically.

In the design for heating and air conditioning systems, fresh or outside air necessary for ventilation of an underground installation represents a portion of the heating and cooling load for the installation. Without a means for determining the temperature of the air at the end of its passage through tunnels or shafts, the designer is forced to rely upon the outside air temperatures for design conditions. The hypothetical problem of section 6 shows that the heating and cooling loads for design purposes are considerably reduced when the temperature of air at the end of a tunnel is predicted by the derived equations. These equations are included in a design manual for military installations [5].

An assumption has been made which develops a degree of uncertainty toward the use of the equations. An effective coefficient of heat transfer value " $h$ " suitable for a particular application may, in most cases, only be determined as an educated guess, because no predictable values for large size tunnel airways are available from literature.

\section{Appendix}

\subsection{Solution of Heat Transfer Problem}

With the boundary conditions as set forth in eqs (1), (2), and (3) of section 2, eq (4) may be obtained by assuming that the temperature in the surrounding solid at a cross section at a distance $x$ from the entrance is

$$
\theta_{r, x}=F e^{i \omega t} \text {, where } F=f(r)
$$

and also that the temperature of the flowing air is:

$$
\theta_{x}=G e^{i \omega t}, \text { where } G=f(x) .
$$

By substituting the appropriate derivatives of eq (7) in the differential equation for conduction of heat radially in a cylindrical system having angular symmetry:

$$
\frac{\partial^{2} \theta}{\partial r^{2}}+\frac{1}{r} \frac{\partial \theta}{\partial r}-\frac{1}{\alpha} \frac{\partial \theta}{\partial t}=0
$$

the latter becomes

$$
F^{\prime \prime}+\frac{1}{r} F^{\prime}-\frac{i \omega F}{\alpha}=0 .
$$

This is the modified Bessel equation of zero order, for which the general solution given in terms of the modified Bessel functions $I_{0}, K_{0}$, is

$$
F=D I_{0}\left(r \sqrt{\frac{i \omega}{\alpha}}\right)+C K_{0}\left(r \sqrt{\frac{i \omega}{\alpha}}\right) .
$$

For $F$ to be finite as $r$ approaches infinity, $D=0$, and a particular solution is: 
and from eq (7),

$$
F=C K_{0}\left(r \sqrt{\frac{i \omega}{\alpha}}\right)
$$

$$
\theta_{r, x}=C e^{i \omega t} K_{0}\left(r \sqrt{\frac{i \omega}{\alpha}}\right) .
$$

Differentiating,

$$
\left(\frac{d \theta}{d r}\right)_{r=a}=-C e^{i \omega t} \sqrt{\frac{i \omega}{\alpha}} K_{1}\left(a \sqrt{\frac{i \omega}{\alpha}}\right) .
$$

Substituting eqs (9) and (10) in eq (3), and solving for $C$, eq (10) becomes:

$$
\left(\frac{d \theta}{d r}\right)_{r=a}=\frac{-\theta_{x} \frac{h}{K} \sqrt{\frac{i \omega}{\alpha}} K_{1}\left(a \sqrt{\frac{i \omega}{\alpha}}\right)}{\sqrt{\frac{i \omega}{\alpha}} K_{1}\left(a \sqrt{\frac{i \omega}{\alpha}}\right)+\frac{h}{K} K_{0}\left(a \sqrt{\frac{i \omega}{\alpha}}\right)} .
$$

Simplify by letting

$$
\begin{aligned}
z & =a \sqrt{\omega / \alpha} \\
K_{0}(z \sqrt{i}) & =N_{0}(z) e^{i \phi_{0}(z)} \\
\sqrt{i} K_{1}(z \sqrt{i}) & =N_{1}(z) e^{i\left\{\phi_{1}(z)+\frac{\partial \pi}{4}\right\}} \\
n & =a h / K \\
P & =z \frac{N_{1}(z)}{N_{0}(z)} \\
\mu & =\phi_{1}(z)+\frac{\pi}{4}-\phi_{0}(z) .
\end{aligned}
$$

Where values of the functions of $N_{0}(z), N_{1}(z), \phi_{0}(z)$, and $\phi_{1}(z)$ are given by McLachlen and Meyers [6], eq (10a) becomes

$$
-\left(\frac{d \theta}{d r}\right)_{r=a}=\frac{\left(\theta_{x}\right)}{a} \frac{n P e^{i(\mu+\pi / 2)}}{n+P e^{i(\mu+\pi / 2)}} \cdot
$$

Rationalizing and further simplifying, eq (3) becomes

$$
\begin{aligned}
-K\left(\frac{d \theta}{d r}\right)_{r=a} & =\frac{K \theta_{x}}{a} \frac{P-n \sin \mu+i n \cos \mu}{\frac{n}{P}+\frac{P}{n}-2 \sin \mu} \\
& =\frac{K \theta_{x}}{2 \pi a}\left(A^{\prime}+i B^{\prime}\right)=h\left(\theta_{x}-\theta_{a, x}\right)
\end{aligned}
$$

where

$$
\begin{aligned}
& A^{\prime}=\frac{2 \pi(P-n \sin \mu)}{\frac{P}{n}+\frac{n}{P}-2 \sin \mu},(\text { fig. 1) } \\
& B^{\prime}=\frac{2 \pi n \cos \mu}{\frac{P}{n}+\frac{n}{P}-2 \sin \mu},(\text { fig. 1). }
\end{aligned}
$$

Substituting the above in eq (2)

$$
V \frac{d \theta_{x}}{d x}+\frac{d \theta_{x}}{d t}+\frac{K \theta_{x}}{2 \pi M^{\prime} c^{\prime} a}\left(A^{\prime}+i B^{\prime}\right)=0 .
$$

Substituting from eq (8),

$$
V G^{\prime}+i \omega G+\frac{G K}{2 \pi M^{\prime} c^{\prime} a}\left(A^{\prime}+i B^{\prime}\right)=0 .
$$

Letting $A=\frac{K x}{2 \pi a V M^{\prime} c^{\prime}}=\frac{K x}{W^{\prime} c^{\prime}}$

the solution of the differential equation is:

$$
G=J e\left[-\frac{i \omega x}{V}-A\left(A^{\prime}+i B^{\prime}\right)\right] .
$$

Substituting in eq (9),

$$
\theta_{x}=J e\left[i \omega t-\frac{i \omega t}{V}-A\left(A^{\prime}+i B^{\prime}\right)\right]
$$

Equation (1) states:

then

$$
\theta_{0}=\theta_{i}+\Delta e^{i \omega t}
$$

$$
J=\Delta+\theta_{i} e^{i \omega t} .
$$

Making this substitution,

$$
\theta_{x}=e^{-A A^{\prime}}\left[\Delta e^{i}\left(\omega t-\frac{\omega x}{V}-A B^{\prime}\right)+\theta_{i} e^{-\imath}\left(\frac{\omega x}{V}+A B^{\prime}\right)\right] .
$$

Considering only the real part,

$\theta_{x}=e^{-A A^{\prime}}\left[\Delta \cos \left(\omega t-\frac{\omega x}{V}-A B^{\prime}\right)+\theta_{i} \cos \left(\frac{\omega x}{V}+A B^{\prime}\right)\right]$.

For frequencies $\omega$ under consideration, the term $\omega x / V$ is negligible and a closely approximate solution is

$$
\theta_{x}=e^{-A A^{\prime}}\left[\Delta \cos \left(\omega t-A B^{\prime}\right)+\theta_{i} \cos A B^{\prime}\right] .
$$

Without giving the derivation from eq (9), the temperature at radius, $r$, in the solid surrounding the tunnel is :

$$
\theta=\Delta e^{-A A^{\prime}} \frac{N_{0}(R)}{N_{0}(z)} \frac{\cos (\omega t+S-\tau)+\frac{\theta_{i}}{\Delta} \cos (S-\tau)}{\sqrt{\left(\frac{P}{n}\right)^{2}+1-2 \frac{P}{n} \sin \mu}}
$$

where

$$
\begin{aligned}
R & =r \sqrt{\omega / \alpha}=r z / a \\
S & =\phi_{0}(R)-\phi_{0}(z)-A B^{\prime} \\
\tau & =\tan ^{-1} \frac{\cos \mu}{\frac{n}{P}-\sin \mu} .
\end{aligned}
$$




\subsection{Air Heat Exchange}

At any time, $t$, the rate at which heat is lost by the flowing air is:

$$
q=W^{\prime} c^{\prime}\left(\theta_{0}-\theta_{x}\right) .
$$

The maximum rates of cooling and heating of the air are given by

$$
\begin{aligned}
q_{m}=W^{\prime} c^{\prime}\left[ \pm \Delta \sqrt{1+e^{-2 A A^{\prime}}-2 e^{-A A^{\prime}} \cos A B^{\prime}}\right. & \\
& \left.+\theta_{i}\left(1-e^{-A A^{\prime}} \cos A B^{\prime}\right)\right] .
\end{aligned}
$$

If it is assumed that $\cos A B^{\prime} \cong 1.0$, then

$$
q_{m}=W^{\prime} c^{\prime}\left(1-e^{-A A^{\prime}}\right)\left( \pm \Delta+\theta_{i}\right) .
$$

The average rate of heat flow for a given cooling or heating cycle is:

$$
q_{a n}=W^{\prime} c^{\prime}\left(1-e^{-A A^{\prime}}\right)\left( \pm \frac{2 \Delta}{\pi}+\theta_{i}\right) .
$$

\subsection{Symbols}

Unless otherwise labeled, quantities are dimensionless when consistent units are used:

$A=K x / W^{\prime} c^{\prime}$,

$A^{\prime}=\frac{2 \pi(P-n \sin \mu)}{\frac{n}{P}+\frac{P}{n}-2 \sin \mu}$, plotted on figure 1 as a function $n$ and $z$,

$a=$ radius of hollow cylinder, $\mathrm{ft}$,

$=2(\operatorname{cross}$ section $) /($ perimeter $)$, for noncircular cylinders,

$B^{\prime}=\frac{2 \pi n \cos \mu}{n} P$, plotted on figure 1 as a function $\frac{n}{P}+\frac{P}{n}-2 \sin \mu \quad$ of $n$ and $z$,

$c=$ specific heat of surrounding solid, $\mathrm{Btu} / \mathrm{lb}-{ }^{\circ} \mathrm{F}$,

$c^{\prime}=$ specific heat of air flowing in cylinder, $\mathrm{Btu} / \mathrm{lb}-{ }^{\circ} \mathrm{F}$,

$e=$ base of Naperian (natural) logarithms,

$h=$ coefficient of heat transfer between air and surface of cylinder, Btu/hr- $\mathrm{ft}^{2}{ }^{\circ} \mathrm{F}$,

$K=$ thermal conductivity of surrounding solid, $\mathrm{Btu} / \mathrm{hr}-\mathrm{ft}-{ }^{\circ} \mathrm{F}$,

$M^{\prime}=$ weight of fluid (air) per unit of surface area of cylinder, $\mathrm{lb} / \mathrm{ft}^{2}$,

$n=a h / K$,

$P=z N_{1}(z) / N_{0}(z)$,

$q=$ heat flow rate from air to tunnel wall, Btu/hr, $r=$ radius, $\mathrm{ft}, !$
$T=$ temperature, ${ }^{\circ} \mathrm{F}, \quad T_{0}$ is temperature of air entering tunnel; $T_{i}$ is annual mean value of $T_{0} . \quad T_{s}$ is the steady temperature of the deep underground rock remotely surrounding the tunnel,

$t=$ time, hr,

$V=$ velocity in tunnel, $\mathrm{ft} / \mathrm{hr}$,

$W^{\prime}=$ weight rate of air flow, lb/hr,

$x=$ distance from entrance of tunnel, $\mathrm{ft}$,

$z=a \sqrt{\omega / \alpha}$

$\alpha=$ thermal diffusivity of surrounding solid, $\mathrm{ft}^{2} / \mathrm{hr}$,

$\Delta=$ amplitude of annual variation of $T_{0}$ about the mean value $T_{i},{ }^{\circ} \mathrm{F}$,

$=\left(T_{0(\max )}-T_{i}\right)=1 / 2\left(T_{0(\max )}-T_{0(\min )}\right)$,

$\mu=\phi_{1}(z)+\pi / 4-\phi_{0}(z)$,

$\theta=$ subrogated temperature, equal to $\left(T-T_{s}\right),{ }^{\circ} \mathrm{F}$,

$\theta_{i}=$ subrogated annual mean entering air temperature, equal to $\left(T_{i}-T_{s}\right),{ }^{\circ} \mathrm{F}$,

$\omega=$ angular velocity, radian $/ \mathrm{hr}$.

Temperatures at various positions are indicated by the subscripts:

$0=$ at tunnel inlet $(x=0, r<a)$,

$x=$ at distance $x$ from tunnel inlet $(r<a)$,

$L=$ at tunnel outlet $(x=L, r<a)$,

$r, x=$ at radius $r$ at distance $x$ from tunnel inlet $(r \geq a)$,

$a, x=$ at tunnel surface $(r=a)$ at distance $x$ from inlet.

The subscript $m$ denotes a maximum or minimum value.

\section{References}

[1] G. E. MeElroy, Ventilation of the large copper mines of Arizona, U.S. Bur. Mines Bull. 330, 138 (1931).

[2] G. E. McElroy, Engineering factors in the ventilation of metal mines, U.S. Bur. Mines Bull. 385, 90 (1935).

[3] J. M. Craddock, The representation of the annual temperature variation over central and northern Europe by a two-term harmonic form, Quart. J. Roy. Met. Soc. 82, 275 (1956).

[4] W. H. McAdams, Heat transmission, Section Edition, 170, Equation (4f) (McGraw-Hill Book Co., Inc., New York, N.Y.).

[5] Heating and air conditioning of underground installations, EM 1110-345-450, Office of the Chief of Engineers, U.S. Army, 49 (Nov. 30, 1959).

[6] N. W. MeLachlen and A. L. Meyers, The polar form of the ker and kei functions with applications to eddy current heating, Phil. Mag. 120, 610 (1934).

(Paper 65C3-66) 